\title{
BIOETIK: MANFAAT DAN TANTANAN BAGI ETIKA KRISTIANI
}

\author{
John Jeramu \\ Program Studi Ilmu Filsafat, Fakultas Filsafat Universitas Katolik Widya Mandira \\ Jl. Prof. Dr. Herman Yohanes - Penfui - Kupang - NTT \\ Email: johnjeramu81cmf@gmail.com
}

\begin{abstract}
Currently science is found in a paradoxical situation: the basis of scientific activity and the interrelations between science, technology, industry, society and State are strongly questioned and criticized, at the same time that the worldly idea of science as the only motor for human development prevails. There is where the idea of bioethics arises as trans-disciplinary knowledge-for, to and from life-as another way of doing and producing knowledge. This article will explain about the relationship between bioethics and Christian ethics. In particular way, to see the impact and contribution of bioethics for Christian ethics. Dialogue of both is so necessary to respond the challenges of the accelerate progress of biomedicine and biotechnology, and in the same time, to put the ethics limits for technological progress in our times today. It is the way to reach a science and technology development that more responsibility, while respecting for human life and dignity. The fundamental question to be answered through this article is whether the bioethics is a problem or a solution for the human ethics today?
\end{abstract}

Keywords: bioethics, Christian ethics, dialogue-interdiciplines, responsibility, human dignitiy

\section{Pendahuluan}

"Ada dimensi eksistensi manusia yang melampui batas-batas kapasitas yang ditetapkan oleh scientifik teknologi. Jika dilampaui batas-batas tersebut, maka dapat menyebabkan martabat dan kesucian hidup manusia takluk pada pada pertimbangan yang semata-mata utilistaristik» ((Benedicto XVI) ${ }^{1}$

\section{Ke-galau-an Etis: Bioteknologi Tanpa Batas?}

Dalam beberapa dasawarsa terahkir, perkembangan dan kemajuan bioteknologi mengalami sebuah akselerasi yang sangat mengagumkan, tremendum et fascinosum. Pada tanggal 25 Juli 1978, sekelompok ilmuwan Inggris membuat dunia tercengang; para ilmuwan ini mempersembahkan kepada dunia hasil bayi tabung untuk pertama kalinya dalam sejarah dunia medis. Anak pertama hasil bayi tabung ini adalah Louise Brown. Kelahiran ini menandai dan membuka sebuah era baru dalam sejarah teknologi reproduksi. Ini sebuah "loncatan maut" yang melampui hukum natural manusia: seorang bayi yang dikandung dan dilahirkan bukan dari rahim seorang ibu, melainkan dari sebuah laboratorium ${ }^{2}$.

\footnotetext{
${ }^{1}$ Pernyataan ini dimaklumkan oleh Paus Benediktus XVI pada saat audensi 12 November 2011 yang dialamatkan kepada peserta Konferensi Internasional tentang sel-sel induk, yang diorganisir oleh Dewan Pontifikal Untuk Budaya.

2 Dalam beberapa dasawarsa terahkir, sudah ribuan anak dilahirkan melalui program bayi tabung.
} 
Keajaiban bioeteknologi juga terjadi di USA pada tahun 1985, yang dkenal dengan nama kasus "Baby M": keluarga Stern, yang istrinya mandul, meminjam rahim seorang nyonya bernama Mary Whitehead untuk mengandung dan melahirkan anak bagi mereka, dengan bayaran 100.000 USA dolar. Inilah kasus rahim kontrak (subrogation maternity) pertama dalam sejarah bioetik ${ }^{3}$. Dewasa ini, ada banyak pasangan (kelurga kaya dan berasal dari negara barat) melakukan "turismo-bisnis reproduksi" ke negara-negara miskin di Asia, khususnya India, untuk meminjam rahim dan melahirkan anak bagi mereka dengan bayaran yang cukup menggiurkan ${ }^{4}$.

Di satu sisi, kemajuan science dan teknologi ini membawa dampak positif bagi kehidupan: kesejahteraan dan kualitas hidup manusia semakin baik. Namun, di sisi lain, akselerasi bioteknologi yang "tak terkontrol" dan "tanpa batas" dapat membawa dampak negatif bagi manusia dalam berbagai aspek kehidupannya. Pernyataan Paus Emeritus Benediktus XV di bagian awal tulisan ini secara eksplisit mengafirmasi sebuah "ke-galau-an etis": di manakah batas scope-ruang gerak Bioteknologi? Apakah segala sesuatu yang dapat diciptakan dalam tataran scientific dan teknik adalah juga licit (layak) secara moral? Akselerasi dan kreasi bioteknologi yang "tidak tahu batas" dan "sebebas-bebasnya" dapat mengancam martabat dan kesucian hidup manusia.

Kegalauan etis inilah yang menjadi back ground lahirnya Bioetik dalam pentas etika modern. Menurut Javier Gafo, SJ, Teolog Moral Spanyol: "Bioetik memuat penerapan prinsip-prinsip etis dalam dunia scientific dan teknik; Bioetik berfungsi sebagai "kompas" yang mengarahkan kemajuan Bioteknologi secara manusiawi, dan sekaligus sebagai alat kontrol agar kemajuan Bioteknologi tidak bertentangan dengan martabat manusia"5.

Bertolak dari kegalauan etis itu, penulis mencoba menjawab status question yang akan dikaji dalam tulisan ini: sejauh mana kontribusi/manfaat Bioetik dan tantangannya bagi Etika Kristiani? Apakah Bioetik merupakan jawaban atau persoalan bagi nilai kemanusian?

\section{Pembahasan}

\subsection{Tinjauan Global Tentang Biotek}

Bioetik merupakan disiplin ilmu yang mulai muncul pada tahun 1960-an di Amerika Serikat. Pada era itu timbul persoalan-persolan baru dalam etika, yang dipicu

\footnotetext{
${ }^{3}$ Cf. P. F. SILVA-RUIZ, El contrato de maternidad sustituta o suplente o subrogada, la maternidad de alquiler, BIMJ 1447 (1987), 3-4.

${ }^{4}$ India menjadi salah satu negara destinasi favorit bisnis rahim kontrak dewasa ini. Realitas kemiskinan dan bayaran yang cukup mahal memungkinkan semakin merebaknya bisnis rahim ini. Ada sekitar 350 klinik swasta yang menyediakan layanan jasa rahim kontrak tersebut. Apalagi sejak tahun 2002 konstitusi India melegalkan bisnis rahim kontrak karena mendatangkan income yang cukup tinggi bagi negara, yang mencapai kisaran 2 miliyar dolar per tahun (Cf. M. AMADOR JIMÉNEZ, Biopoliticas y biotecnologías: maternidad subrogada en India, RN (2011) 37-38).

${ }^{5}$ J. Gafo, Bioética Teológica, Bilbao-Spanyol: Desclee de Brouwer, 2002, hlm. 6.
} 
oleh kemajuan science dan teknologi. Persoalan-persoalan baru tersebut misalnya eksperimen ilmiah yang menjadikan manusia kelinci percobaan penemuan código genética (DNA), ancaman nuklir, krisis ekologi, peningkatan kepadatan penduduk. Lahirnya bioetik ini dipelopori oleh V. R. Potter $^{6}$ dan A. Hellegers ${ }^{7}$.

Term bioetik terbentuk dari kata Yunani: "bios" (hidup) dan "ethos" (adat istiadat, kebiasaan, akhlak, watak, cara berpikir). Jadi, secara harafiah bioetik berarti etika hidup. ${ }^{9}$ Dalam kenyataannya, istilah bioetik mengandung pemaknaan dan penafsiran yang plural dan bervariasi. Para medis memahami bioetik sebagai wajah baru dari deontologi profesi atau etika medis; para biolog melihat bioetik sebagai kesadaran sosial yang baru tentang kehidupan; dan para ekolog memahami bioetik sebagai kepekaan moral berhadapan dengan berbagai ancaman terhadap lingkungan hidup $^{10}$.

Menurut Encyclopedia of Bioethics, "bioetik merupakan sebuah studi sistematis tentang prilaku manusia pada area biologi dan kesehatan, di mana prilaku tersebut dinilai atau diverifikasi berdasarkan nilai-nilai dan prinsip-pinsip moral"11. Menurut F. Abel, "bioetik merupakan studi interdisipliner tentang masalah yang ditimbulkan oleh perkembangan di bidang biologi dan ilmu kedokteran baik skala mikro maupun makro, masa kini dan masa mendatang"12. Dan Marciano Vidal, Teolog moral katolik asal Spanyol, memberikan definisi bioetik secara komprehensif dan holistik: "la bioética es la ciencia que estudia crítica, sistemática $e$ interdisciplinarmente la conducta humana, tanto individual como social, en relación

\footnotetext{
${ }^{6} \boldsymbol{V} . \boldsymbol{R}$ Potter (1911-2001) mempelopori lahirnya "Global Boiethics" atau "Ecology Bioethics". Melalui karyanya, "Bridge to future" (1971), dia menegaskan bahwa krisis ekologi yang sedang terjadi melanda dunia secara global disebabkan oleh kemajuan teknologi yang tanpa dibatasi oleh nilai-nilai dan prinsip-prinsip etis. Oleh karena itu, kehadiran bioetik merupakan sebuah keharusan. Menurutnya, bioetik merupakan "jembatan" yang menghubungkan dua budaya: biologi dan nilai kemanusian. Bioetik merupakan solusi dan jawaban untuk menyelamatkan dunia global dari terjangan krisis ekologi. Bioetik menjadi jembatan yang mengantar umat manusia kepada dunia masa depan yang lebih baik (Ferrer J. J.-ÁlvareZ, J. C., Para fundamentar la bioética. Teorías y paradigmas teóricos en la bioética contemporánea, Madrid: U. P. Comillas, 2003, hlm. 61-62)

${ }^{7}$ A. Hellegers adalah pendiri Kennedy institute. Dia menawarkan sebuah bioetik yang berbeda dari V. R. Potter, yakni bioetik medis atau klinis. A. Helllegers menerapkan prinsip-prinsip etis berkaitan dengan kemajuan bioteknologi dalam dunia medis. Bioetik klinis biasa disebut juga "bioetik Georgetown" (Ibid., 63-64).

${ }^{8}$ Secara luas, dirumuskan tiga makna kata etika: Pertama, etika sebagai sistem nilai-nilai dan normanorma moral yang menjadi pegangan bagi seseorang atau sekelompok orang dalam mengatur tingkah lakunya. Kedua, etika berarti sebagai kode etik atau kumpulan asas dan nilai moral; Ketiga, etika sebagai filsafat moral yakni refleksi sistematis-kritis dan filosofis akan kebiasan, norma-norma moral dan prilaku moral manusia.

${ }^{9}$ William Chang, OFM Cap., Bioetika Sebuah Pengantar, Yogyakarta: Kanisius, 2019, hlm. 13.

${ }^{10} \mathrm{Cf}$. Eugenio Alburquerque, 25 Preguntas Sobre La Bioética, Madrid: Editorial CCS, 2010, hlm. 11.

${ }^{11}$ W. T. REICH, Encyclopedia of Bioethics, Londres-Nueva York, 1978, 33-34.

${ }^{12} \mathrm{~F}$. ABEL, Bioética: origen y desarrollo, en AA. VV., La vida humana: origen y desarrollo. Reflexiones bioéticas de científicos y moralistas, Madrid-Barcelona, 1989, hlm. 14.
} 
con los problemas creados en el área de la vida por el desarrollo tecnológico, a la luz de los valores y principios éticos"13.

Walaupun merupakan sebuah disiplin ilmu yang terbilang baru, bioetik kini telah menjadi semacam gerakan baru yang melanda seluruh dunia. Kehadiran dan urgensinya tidak bisa dilepaskan dari perkembangan ilmu pengetahun, khususnya biologi dan ilmu kedokteran yang menimbulkan masalah-masalah etis yang luar biasa. Bioetik, yang merupakan kombinasi antara pengetahuan hayati (biologi) dengan pengetahuan sistem nilai manusia, berkontribusi membangun jembatan antara ilmu pengetahuan dan humaniora (kemanusiaan), membantu "kemanusiaan" untuk tetap selamat dan lestari, serta memungkinkan terciptanya dunia yang lebih bermartabat dan manusiawi.

\subsection{Bioetik: Manfaat dan Tantangan Bagi Etika Kristiani}

\section{Relasi Bioetika dan Etika Kristiani}

Ada relasi yang erat dan tak terpisahkan antara bioetik dan etika kristiana. Keduanya memiliki objek yang sama, yakni berkaitan dengan "hidup manusia". De facto keduanya memiliki metodologi dan epistemologi propium, namun dalam banyak aspek keduanya saling melengkapi dan memperkaya satu sama lain.

Pada hakekatnya bioetik berkarakter interdisipliner. Meskipun terlahir dari kemajuan di bidang biomedis yang berkaitan dengan persoalan-persolan manusia dan sosial, namun bioetik membutuhkan refleksi etis, termasuk etika kristiani. Kehadiran etika kristiani dapat memperkaya bioetik dalam merefleksi dan menyikapi secara baik akan kemajuan science dan teknologi.

Dalam sejarah dan tradisi etika kristiani selalu ada kepedulian terhadap persoalan-persoalan kemanusian berkaitan dengan kehidupan, kematian, kesehatan dan orang sakit. Pada abad-abad silam sudah muncul traktat tentang moral medis dan pastoral medis. Lahirnya gerakan bioetik, pada tahun 1960-an, tidak terlepas dari keterlibatan para moralis dari kalangan religius (Yahudi, Protestan, Katolik). Moral Kristiani, khususnya, mendukung dan kolaborasi dalam refleksi interdisiplinar yang menggerakan progresivitas scientifik. Aportasi spesifik etika kristiani berkaitan dengan "discerment moral" yang bersumber pada "akal budi yang diterangi oleh iman" di mana "iman menyinari segala sesuatu dengan cahaya baru, dan memaparkan rencana ilahi tentang keseluruhan panggilan manusia; oleh karena itu membimbing akal budi ke arah cara-cara memecahkan soal yang sangat manusiawi" (GS 11). Namun iman tidak menghilangkan rasionalitas; sebaliknya, akal budi menjadi starting point fundamental untuk memahami problem-problem moral. Secara sintetik, bisa dikatakan bahwa pendekatan etis teologi moral direalisir melalui "terang Injil dan pengalaman manusia" (GS 46).

\footnotetext{
${ }^{13}$ M. VIDAL, Bioética. Estudios de bioética racional, Madrid 1989, 16. Terjemahan harafiahnya: "Bioetik adalah sebuah studi kritis, sistematis dan interdisiplinar tentang prilaku manusia, entah individual maupun sosial, berkaitan dengan permasalahan-permasalahan yang muncul dalam area kehidupan karena perkembangan teknologi, dalam terang nilai-nilai dan prinsip-prinsip etis".
} 
Akan tetapi refleksi etis bukanlah warisan eksklusif zona religius. Perdebatan bioetis terjadi dalam konteks masyarakat plural; bioetik lebih bersifat atau berkaitan dengan etika sekular, yang berpatokan pada akal budi dan otonomi pribadi. Bioetik berkarakter rasional, dengan mengedepankan keempat prinsip etis fundamental, sebagaimana diajukan dalam el Informe de Belmont (1948) dan Beauchamp dan Childress ${ }^{14}$ : Pertama. Non-maleficience: tidak merusak/ tidak berbuat jahat. Merupakan obligasi/keharusan untuk tidak "berbuat jahat/merusak" secara sadar dan sengaja. Prinsip "Non-maleficience" berkaitan erat dengan "Sumpah hipokratik"15. "primum non nocere" (pertamatama adalah "tidak merusak); Kedua, Beneficience: prinsip keuntungan, kesejahteraan, kebaikan. Prinsip benefience menuntuk kita untuk melakukan suatu tindakan positif yang menghasilkan kebaikan bagi orang lain; Ketiga, Otonomi ${ }^{16}$ : prinsip yang menekankan kebebasan, kemandirian dan keyakinannya, tanpa bergantung atau dipaksa oleh orang, dalam mengambil sebuah keputusan. Prinsip otonomi juga berarti "bebas dari" "kelemahan-kelemahan" personal yang menghalangi seseorang mengambil sebuah keputusan yang benar; Keempat, Keadilan (Justice): Prinsip yang menekankan proporsionalitas antara hak dan kewajiban. Sebuah keadilan yang tidak memperlakukan semua kasus secara sama, tetapi diperlakukan-ditangani sesuai dengan situasi, kondisi dan kebutuhannya.

Maka pada hakekatnya, bioetik membantu etika kristiani agar mampu berdialog dengan etikaetika nonkristiani, karena pendasarannya berlandaskan pada refleksi rasional dan manusiawi. Namun, bioetik juga membutuhkan aportasi dari etika kristiani. Iman kristiani berkontribusi bagi pendasaran dan kedalaman refleksi etis dalam bioetik. Jadi relasi keduanya bersifat komplementer. Keduanya bukanlah merupakan dua disiplin ilmu yang berbeda, melainkan disiplin yang sama tetapi dengan perspektif yang berbeda.

\subsection{Kontribusi Bioetik bagi Etika Kristiani}

\section{Kontribusi Epistemologis: Interdisiplinar}

Bioetik berkarakter interdisiplinar. Meskipun terlahir dari kemajuan dalam bidang biomedis, tetapi juga berkaitan erat dengan persoalanpersoalan manusia dan sosial. Maka secara epistemologis, bioetik berdialog dengan disiplindisiplin ilmu lainya, seperti Filsafat, Biologi, Psikologi, Sosiologi, Budya, etc. Prinsipprinsip etis dalam bioetik lebih bersifat universal dan plural, yang bisa ditujukan dan diterima oleh semua orang.

Karakter interdisiplinar bioetik secara tidak langsung membawa pergeseran dan perubahan epsitemologi dan paradigmaperspektif dalam etika kristiani. Munculnya

\footnotetext{
${ }^{14}$ Cf. J.J. Ferrer J. C. Alvarez, Op.cit., hlm.131133

15 "Sumpah hipocrátik": Melarang para medis untuk melakukan praktek aborsi, eutanasia dan operasi; larangan untuk menjalin relasi seksual dengan para pasien dan bersumpah untuk menjaga rahasia data-data personal dari pasien (el secreto profesional) (J.J. Ferrer J. C. Alvarez, Ibid., hlm.130).

16 Konsep "otonomi" lahir dari "konteks politik" (Revolusi Prancis), yang kemudian diterapkan dalam konteks klinis.
} 
persoalanpersoalan baru dalam bidang biomedis dan bioteknologi (misalnya, teknikteknik reproduksi artificial, transpalantasi, kloning, eutanasia, etc..) mendorong etika kristiani untuk membuka diri terhadap disiplindisiplin ilmu lain, sehingga bisa memahami persoalan moral secara komprehensif dan objektif, dan pada ahkirnya dapat memberikan sebuah penilaian etis yang baik dan benar. Tidaklah cukup kalau etika kristiana hanya mendasarkan diri pada Kitab Suci, Tradisi atau magisterium abad pertengahan. Refleksi teologi moral kristiani hendaknya bersumber pada "Terang Injil dan pengalaman manusia" (GS 46). Refleksi Etika Kristiani hendaknya memadukan iman dan akal budi: credo ut inteligam, intellege ut credam" (aku percaya supaya lebih mengerti, dan aku mengerti supaya lebih percaya).

Kontribusi interdisiplinar bioetik ini sangat nampak dalam ajaran etika kristiani dalam beberapa dasawarsa terahkir. Konsili Vatikan II melahirkan "revolusi global" sekaligus "revolusi mental" dalam kehidupan menggereja, termasuk dalam ajaran Teologi Moral Kristiani. Konsili menyadari situasi aktual dunia dewasa ini, di mana ada perubahan situasi yang mendalam: perkembangan pesat ilmu matematika, biologi, psikologi, sosiologi dan teknologi. Mentalitas ilmiah sedang menguasai zaman kita. Perkembangan yang pesat dari ilmu ini melahirkan cara berpikir, cara hidup dan mental baru dalam kehidupan manusia (cf. GS 5). Perkembangan yang pesat ini juga bisa membantu kita untuk semakin mengenal lebih mendalam tentang kodrat manusia (cf. GS 44).

Konsili menegaskan bahwa pesan-pesan Injili harus disampaikan dengan menggunakan kategori-kategori aktual sehingga bisa dimengerti dan diterima oleh manusia zaman sekarang. Perhatian Teologi Moral terhadap ilmu-ilmu humaniora tidaklah "menurunkan derajat" misinya, tetapi justru sungguh membantu panggilan teologis dan pewartaan Gereja. Hal ini kembali dikonfirmasi oleh Paus Yohanes Paulus II dalam ensiklik "Veritas Splendor" no. 29b: "Dalam reksa pastoral hendaknya jangan hanya asas-asas teologi, melainkan penemuan-penemuan ilmupengetahuan profan jugalah, terutama psikologi dan sosiologi, yang diakui dan digunakan secukupnya, sehingga umat berimanpun diantar kepada kehidupan iman yang lebih murni dan dewasa" (cf. GS 62)

Selain itu, bioetik membangun relasi interdisiplinar dengan berbagai aliran filsafat. Jika sebelum reformasi Konsili Vatikan II, Teologi Moral Kristiani didominasi oleh Filsafat Skolastik St. Tomas Aquinas, namun sejak KV II etika kristiani mulai membuka diri terhadap aliran filsafat lainnya. Ini adalah sebuah progresivitas yang luar biasa, di mana etika kristiani mulai terbuka terhadap "pluralisme filosofis". Namun KV II mengingatkan bahwa etika kristiani tetap bersikap "selektif" dan bijaksana: menerima aportasi pemikiran filosofis yang cocok-sesuai dengan prinsip iman-moral kristiani, dan menolak yang bertentangan atau tidak relevan dengannya. Demikian juga dianjurkan oleh Yohanes Paulus II dalam "Fides et Ratio": perlunya melakukan "discerment" terhadap asumsi-asumsinya, karena keanekaragaman metode hermeneutik berlandaskan pada konsep-konsep filosofis (FR. 55).

\section{Membuka Diri dan Berdialog Dengan Aliran Etika Lainnya}

Bioetik terlahir dalam sebuah kontek etis yang sangat plural. Dia terlahir bukan dalam konteks religius, melainkan konteks sipil. Bioetik bukanlah sebuah etika yang 
tercipta untuk satu agama tertentu, melainkan diperuntukkan bagi semua orang, berkaitan dengan "vita commune". Bioetik mendefinisikan dirinya sebagi "etica civil" atau "etica minimum". Atau menurut A. Cortina, seorang teolog moral spanyol, bioetik merupakan sebuah "etica del cuidadano" (etika kewarganegaraan), artinya etika kewarganegaraan dalam sebuah masyarakat plural, dimana prinsip-prinsip moralnya bisa diterima oleh semua orang dari berbagai kalangan agama/suku, yang memungkinkan terciptanya toleransi dalam kehidupan bersama sebagai warga negara ${ }^{17}$. Etika ini memuat nilai-nilai moral bersama, yang paling kurang, sesuai dengan nilai dan prinsip etika yang ada pada setiap agama atau kelompok social umumnya, misalnya berkaitan dengan penghormatan terhadap martabat manusia, hakhak asasi manusia, keadilan, toleransi, solidaritas, etc.

Etika sipil atau etika minimum ini membantu Etika Kristiani untuk berdialog dengan etika lain dari agama atau budaya yang berbeda. Dialog intereligius dan intercultural ini membantu etika kristiani untuk bersikap positif terhadap prinsipnilai etis yang ada pada budaya/agama lain, berusaha untuk membagi nilainilai etis comun, dan juga menghargai perbedaanperbedaan di dalamnya. Keanekaragaman nilai etis bukannya untuk diperdebatkan atau menjadi sumber pertentangan, melainkan bisa saling melengkapi dan memperkaya refleksi etis setiap agama/budaya, dengan tetap berpegang teguh pada prinsipprinsip fundamental etikanya masing-masing.

Meskipun demikian, etika kristiani tetap memiliki tanggungjawab untuk berusaha, melalui cara-cara yang kontruktif dan manusiawi, agar nilai etis maximum kristiani bisa menjadi bagian dari etica sipil dan bisa menginspirasi dan memperkaya etikaetika non kristiani. Kesaksian dan teladan hidup seorang kristiani yang setia dan komitmen terhadap etika kristiani, memungkinkan membawa pembaharuan dan "pertobatanpemurnian etis" bagi etika sipil dan etika non kristiani lainnya ${ }^{18}$. Inilah salah satu panggilan dan karya evangelisasi etika kristiani; dimana nilainilai injili dapat diterima dan dihayati oleh semua orang, sehingga semakin tercipta sebuah kehidupan dan dunia yang lebih baik dan manusiawi.

\section{Sebuah Etika Kristiani Ber-Vision Global dan Aggiornamiento}

Sebelum muncul bioetik, etika kristiani kerapkali bersikap negatif dan bernada psimistis terhadap perkembangan dan kemajuan ilmu pengetahun scientifik. Sebuah etika yang kadang terjebak dalam "urusan kepentingan dirinya", tanpa peduli bahkan menjauhkan diri dari kebutuhan dan persoalan manusia actual. Selain itu, etika kristiani kerapkali menggunakan "bahasa" atau "cara berkomunikasi" yang terlalu "filosofis, kanonis dan liturgis", sehingga tidak dimengerti oleh manusia actual dan sangat jauh dari realitas harian manusia ${ }^{19}$.

Maka dalam arti tertentu, bioetik telah "menyelamatkan" etika kristiani dari ketertutupannya akan perkembangan dan kemajuan dunia. Bioetik telah membantu dan mendorong etika kristiani untuk terbuka dan peduli akan realitas dan problem

\footnotetext{
${ }^{17}$ A. CORTINA, Ética civil y religión, Madrid: Ediciones Paulinas, 1995, 12

${ }^{18}$ Cf. A. CORTINA, Ética mínima y éticas religiosas de máximos, en P. M. SARMIENTO - L. Grosso (eds.), No apaguéis el Espíritu. Nuestra casa encendida, Madrid: Ediciones Paulinas, 1998, 251.

19 Jose Vica Peinado, CMF, Eticas Teologicas ayer y hoy, Madrid: Ediciones Paulinas, 1993, hlm. 15.
} 
kongkret manusia dan dunia aktual. Bioetik membawa reformasi bagi etika kristiana agar terbuka terhadap realitas, kebutuhan dan persoalan kongkret manusia aktual, serta berkomunikasi dengan menggunakan "bahasa etis" yang tidak asing bagi manusia zaman sekarang, sehingga bisa dimengerti oleh semua orang.

Selain itu, bioetik berkontribusi dalam penerapan penerapan prinsip etis kristiani dalam sebuah perspektif global dan kontekstual. Bioetik menawarkan sebuah sistem praktis dalam mengaplikasi prinsip dan kriteria etika kristiani. Bioetik tidak campur tangan berkaitan dengan prinsip dan kriteria propium etika kristiani, melainkan menawarkan sebuah pedoman atau orientasi etis agar mengambil sebuah keputusan moral secara rasional terhadap apa yang harus dilakukan seseorang ketika berhadapan dengan sebuah persoalan moral yang kongkret, sehingga keputusan itu bisa dimengerti dan diterima oleh semua orang.

\section{Memberi Jawaban Etis Yang Rasional dan Aceptable}

Sejak lahirnya bioetik di tahun 60-an, seiring dengan kemajuaan yang pesat dalam biomedis dan bioteknologi, telah muncul berbagai tema moral yang baru: teknik reproduksi artificial, cloning, transplantasi organ, rekayasa genetic, eutanasia, krisis ekologi, etc. Realitas dan situasi yang baru ini membawa persoalan baru dalam kehidupan manusia. Bahkan, kemajuan science dan teknlogi yang tak terbendung ini membawa ancaman bagi nilai kemanusian dan martabat manusia.

Lahirnya bioetik tidak terlepas dari situasi ini. Bioetik terlahir untuk memberikan refleksi kritis terhadap kemajuan science dan teknologi ini, dengan menerapkan prinsip-prinsip. Hadirnya bioetik bertujuan agar perkembangan IPTEK tidak bertentangan dengan nilai-nilai etis fundamental, yakni penghargaan terhadap martabat manusia.

Dalam hal ini bioetik menyadarkan etika kristiani akan realitas baru yang diciptakan oleh kemajuan biomedis dan bioteknologi ini. Kriteria-kriteria etis bioetik yang rasional dan interdisiplinar membantu etika kristiani untuk memahami secara lebih baik dan komprhensif akan situasi dan realitas moralitas di abad modern ini. Hal ini juga mendorong etika kristiani untuk melengkapi dan memperkaya bioetik agar pertimbangan dan keputusan moralnya sungguh-sungguh tidak bertentangan dengan kesucian dan martabat manusia.

\subsection{Bioetik: Tantangan bagi Etika Kristiani}

Kemajuan biomedis dan bioteknologi dalam konteks bioetik membawa tantangan yang besar bagi etika kristiani. Jika tidak disikapi secara kritis dan bijaksana, maka bisa menjadi ancaman bagi pelestarian dan survivenya etika kristiani. Akselerasi boimedis dan bioteknlogi dalam lingkaran bioetik yang "omnipotente" dan "tanpa batas" dapat mengancam kesucian martabat manusia dan nilainilai kemanusian. Ada beberapa tantangan bioetik bagi etika kristiani:

\section{Moral Scientifisme}

Moral scientifisme adalah sebuah konsep moral yang berlandaskan pada apa yang dihasilkan oleh manusia sendiri. Moral diredusir menjadi hal "teknik" belaka, 
dimana yang menjadi pusatnya adalah manusia sendiri. Manusia menjadi tuan atas segala tindakan dan apa yang dihasilkannya. Maka identitas manusia sebagai "homo sapiens" direduksi menjadi "homo faber" dan bermuara pada "homo fabricatus". Mentalitas scientifismeteknisme hanya fokus pada pertanyaan "how", tanpa mempertimbangkan pertanyaan "why"; lebih menekankan bagaimana menghasilkan sesuatu, daripada melihat mengapa dan untuk apa itu dihasilkan ${ }^{20}$.

Kemajuan ilmu scientifik dan teknologi memungkinkan manusia merasa bahwa nasib masa depannya terletak dalam genggamannya sendiri. Science dan teknologi telah menghasilkan berbagai penemuan spektakuler dalam berbagai bidang kehidupan manusa, termasuk dalam bioetik; misalnya teknik reproduksi artificial, penemuan sel induk, transplantasi organ, teknik rekayasa genetik, perawatan medis modern yang bisa memperpanjang hidup seseorang, eutanasia, etc. Di satu sisi, kemajuan dalam dunia bioetik ini adalah sangat positif karena dapat memenuhi kebutuhan dan meningkatkan kualitas hidup manusia.

Namun di sisi lain, hal ini dapat menjadi ancaman bagi nilai kemanusian dan martabat manusia. Kemajuan bioetik tanpa batas dan tak mengindahkan prinsipprinsip etis fundamental sangatlah berbahaya bagi kebaikan manusia itu sendiri. Pertanyaan etis fundamental berkaitan dengan realitas tersebut adalah: Apakah segala sesuatu yang bisa dihasilkan oleh science dan teknologi modern adalah licit secara moral? Di manakah batas science dan teknologi? Apakah demi perkembangan science dan teknologi atau demi kemajuan biomedis dapat melakukan penelitiaan yang mengorbankan nyawa seseorang? Apakah licit secara moral seseorang diciptakan sebagai sarana untuk menyembuhkan atau menyelamatkan orang tertentu? Ketika science dan teknologi menjadikan mentalitas utilitaristik dan pragmatik sebagai kriteria absolut bagi kebenaran moral, maka secara otomatis menegasi kebaikan integral manusia.

Secara etis, hakekat dari science dan teknologi adalah untuk melayani manusia; adalah sarana demi kebaikan dan kualitas hidup manusia. Pribadi manusia memiliki tujuan dalam dirinya sendiri, dan tidak bisa dibenarkan secara moral jika dijadikan sebagai sarana demi tujuan tertentu. Dalam konteks etika kristiani, hidup manusia merupakan nilai fundamental martabat manusia. Demikian ditegaskan dalam Dignitatis Personae: "setiap pribadi manusia, dimulai dari konsepsi sampai pada kematian natural, wajib diakui martabat pribadinya" (no. 1).

Inilah tantangan terbesar bagi etika kristiani. Berhadapan dengan akselerasi dan omnipotentenya biomedis dan bioteknologi dalam lingkaran bioetik, etika kristiani dipanggil untuk melindungi dan membela kesucian dan martabat hidup manusia; merawat dan menjaga hidup manusia dari berbagai ancaman yang memanipulasinya. Etika kristiani terus berdialog dengan ilmu science dan teknologi agar menyadari dan menerima "keterbatasannya"; science dan teknologi hendaknya mengenal "batasbatasnya" dan bertindak dalam koridor prinsipprinsip etis. Selain itu, etika kristiani berusaha mendorong para ilmuwan, para medis untuk bertindak sesuai denga hati nuraninya, sehingga nilai kemanusia dan martabat manusia tidak dikorbankan. Perlu adanya kesadaran hati nurani dan tanggungjawab moral. Sebagaimana dilansir oleh

${ }^{20}$ Juan Masia Clavel, Cuidar Ia Vida, Debates Bioeticos, Barcelona: Herder, 2012, hlm. 17. 
ensiklik Caritas in Veritate no. 70: "ciencia sin conciencia no humaniza; conduce mas bien, a la ruina del hombre" (ilmu pengetahuan tanpa hati nurani, tidak memanusiakan; melainkan membawa kehancuran bagi manusia).

\section{Pluralisme dan Relativisme Etis}

Pluralisme bioetik dewasa ini tidak terlepas dari pluralitas paradigma etis yang melatarbelakanginya, misalnya etika liberalradikal, etika pragmatis, etika personalistis dan etika keutamaan. Pendasaran dan kelekatan bioetik pada etika tertentu akan mempengaruhi pandangan dan pengambilan sikap dalam menghadapi kasuskasus yang muncul dalam hidup manusia ${ }^{21}$. Hal ini sejalan dengan apa yang dikatakan oleh Javier Gafo: "problem fundamental dari bioetik tidaklah berasal dari kemajuan biomedis dan bioteknologi, melainkan berasal dari etika"22. Penerapaan secara absolut sebuah model etika dalam bioetik berdampak negatif bagi nilai kemanusia dan martabat manusia:

Etika liberalradikal menitikberatkan unsur kebebasan mutlak pribadi manusia yang dipandang sebagai nilai unik dan mutlak. Setiap pribadi manusia memiliki otonomi mutlak, menjadi tuan atas dirinya sendiri. Kebebasan dan otonomi pribadi menjadi kriteria mutlak sebuah tindakan etis. Model etika ini memungkinkan menerima praktek aborsi, bisnis organ dan rahim kontrak, eutanasia, asalkan itu dilakukan dengan bebas dan otonom ${ }^{23}$.

Etika pragmatis atau utilitaris menekankan bahwa suatu tindakan dianggap baikbenar secara etis jika hal tersebut membawa kegunaan atau manfaat bagi seeorang. Biasa disebut juga etika proporsionalitas. Misalnya, tindakan aborsi terapeutik dianggap benar secara etis, karena lebih digugurkan dari awal dari nanti dilahirkan dan menderita seumur hidup. Hal yang sama berkaitan dengan praktek eutanasia: seorang penderita yang mengalami penyakit terminal dan tersembuhkan, lebih baik mempercepat kematiannya dengan "mati secara baik" dari menanggung penderitaan yang sangat berat ${ }^{24}$.

Etika personalistis menekankan pribadi manusia merupakan nilai moral yang paling fundamental. Dalam hal ini, setiap pribadi manusia memiliki tujuan dalam dirinya sendiri. Pribadi manusia bukanlah objek dan tidak pernah dijadikan sarana untuk mencapai tujuan tertentu. Oleh karena itu, setiap pribadi harus dihargai martabatnya ${ }^{25}$. Model etika ini menjadi salah satu paradigma etis dalam etika kristiani. Hidup setiap pribadi adalah bernilai dan bermartabat. Setiap pribadi harus dihargai karena kemanusiannya dan karena pribadi manusia adalah gambar dan rupa Allah.

Etika keutamaan merupakan model etika klasik kristiani, yang menekankan bahwa tubuh dan hidup manusia merupakan sebuah keutamaan moral ${ }^{26}$. Maka kasuskasus moral seperti mutilasi, aborsi, eutanasia, hukuman mati, etc., merupakan

\footnotetext{
${ }^{21}$ William Chang, OFM Cap., Op.cit., hlm. 17.

22 Javier Gafo, SJ, Bioética teológica, Madrid: U. P. Comillas, 2000, hlm. 25.

${ }^{23}$ William Chang, OFM Cap., Op.cit., hlm.17 18.

${ }^{24}$ Ibid., hlm. 1819.

${ }^{25}$ Ibid., hlm. 2021

${ }^{26}$ Ibid., hlm. 22
} 
tindakan yang bertentangan dengan nilai fundamental hidup manusia. Namun tubuh dan hidup seseorang bukanlah milik ekslusifnya. Tuhanlah yang menjadi tuan dan pemilik hidup manusia. Maka tindakantindakan tersebut di atas, meskipun dilakukan seseorang secara bebas dan otonom, adalah bertentangan dengan nilai dan prinsip etis. Dan menurut etika ini, meskipun hidup manusia merupakan sesuatu yang fundamental, namun tidak bersifat absolut. Maka adalah benar secara etis jika seseoarang mengorbankan hidupnya demi sebuah nilai atau keutamaan yang lebih tinggi (misalnya, para mártir yang menyerahkan nyawanya demi imannya).

Maka, bioetik yang berlandaskan pada etika liberalradikal dan etika pragmatis/utilitaris, jika diterapkan secara absolut, maka akan membawa persoalan dan ancaman bagi kesucian hidup dan martabat manusia. Namun, kriteria etis dari kedua etika tersebut bisa bermanfaat bagi etika kristiani jika diterapkan secara relatif, tanpa bertentangan dengan martabat pribadi manusia. Dalam situasi tertentu, etika liberal dan pragmatis dapat membantu etika kristiani untuk mengambil sebuah keputusan moral yang lebih baik dan manusiawi.

\section{Tantangan Untuk Menghadirkan Etika Injili (Etika Maximum) Dalam Sebuah Masyarakat Yang Plural}

Bioetik adalah sebuah etika plural dan etika minimum. Boetik menghadirkan sebuah etika universal, yang berlaku dan diterima oleh semua orang. Inilah yang menjadi tantangan bagi etika kristiani, yakni bagaimana membuka diri dan berdialog secara tulus dan jujur dengan etika-etika non kristiani lainnya, tanpa jatuh ke dalam sikap fundamentalisme-konservatisme. Apakah etika kristiani juga bersedia untuk diperkaya dan "ditransformasi" oleh etika-etika tersebut?

Namun di sisi lain, etika kristiani dipanggil untuk menghayati keradikalan hidup injili; sebuah etika máximum yang melampui tuntutan etika mínimum tersebut. Inilah tantangan bagi etika kristiani: di tengah gelombang pluralisme bioetik dewasa ini apakah mampu untuk tetap setia dan komitmen dengan prinsip-prinsip etis fundamental, sebagaimana yang dituntut oleh Injil? Dan apakah etika kristiani, melalui komiten dan kesaksian hidup injili, dapat membawa transformasi dan pemurnian bagi etika-etika non kristiani dalam konteks masyarakat plural dewasa ini. Dengan kata lain, etik kristiani ditantang untuk menerapkan KASIH sebagai norma moralitas yang tertinggi, baik bagi orang kristiani maupun bagi mereka yang non kristiani.

\section{Kesimpulan}

\section{Bioetika, Jawaban atau Persoalan Bagi Nilai Kemanusiaan?}

Secara sintetik bisa disimpulkan bahwa bioetik bisa menjadi jawaban, tetapi juga menjadi persoalan bagi nilai kemanusian. Bioetik dapat menjadi jawaban nilai kemanusian jika bioetik tersebut dilandasi oleh sebuah etika yang sehat dan benar. Hal ini akan melahirkan sebuah bioetik yang senantiasa berkomitmen untuk melindungi, merawat dan memperjuangkan nilai hidup dan martabat manusia.

Sebaliknya, bioetik bisa menjadi sebuah persoalan jika dilandasi oleh sebuah etika yang "tidak sehat dan benar". Prinsip utilitaristik dan pragmatistik, kerapkali 
menyalagunakan bioetik sebagai sarana demi sebuah kepentingan atau interest tertentu. Ketika bioetik dimanupulasi oleh kepentingan ekonomis dan politis, maka hal tersebut otomatis membawa persoalan bagi nilai kemanusian, memperalat harkat dan martabat manusia itu sendiri.

Kesimpulannya, bioetik menjadi jawaban atau persoalan tergantung bagaimana manusia menggunakan dan memanfaatkanya secara baik-benar atau tidak; apakah manusia menggunakannya sesuai dengan prinsip etis yang sehat atau tidak.

\section{Daftar Pustaka}

Bryan Magee, The Story of Philosophy, Yogyakarta: Kanisius, 2008.

C.D.C. Reeve (trans), Plato: Republic, Hackett Publishing Company, Inc., 2004.

E. Berti, Metafore dell'invisible. Ricerche sull'analogia, Morcelliana, Brescia 1984.

E. Goreth, Metaphysik. Eine metodisch-systimatische Grundlegung, Tyrolia, Innsburk 1989.

E. Jüngel - I. U. Dalfehrt (ed), Fides quaerens intellectum.

Frans Magnis-Suseno, 13 Model Pendekatan Etika, Yogyakarta: Kanisius, 1998.

F. Riva, Analogia e univocità in Tommaso de Vio "Gaetano", Vita e Pensiero, Milano 1995.

G. Gentile - G Lombardo (eds), Critica della ragione pura, Laterza, Bari, 1984.

James Garvey, 20 Karya Filsafat Terbesar, Yogyakarta: Kanisius, 2010.

Lorens Bagus, Kamus Filsafat, Jakarta: Gramedia Pustaka Utama, 2005.

Nickolas Pappas, Routledge Philosophy Guide to Plato and the Republic, London: Routledge, 1995.

Ted Honderich (ed.), The Companion to Philosophy, New York: Oxford University Press, 1995. 